\section{I. Introduction}

\title{
Hierarchical Energy Management and Control to Improve the Reliability and Efficiency of Wind Farms Connected to the Grid
}

\author{
Belkacem Belabbas ${ }^{1}$, Mouloud Denaï: ${ }^{2}$ and Tayeb Allaoui ${ }^{1}$ \\ ${ }^{1}$ University of IBN KHALDOUN, Laboratory of L2GEGI, TIARET, ALGERIA \\ ${ }^{2}$ School of Engineering and Computer Science, University of Hertfordshire, Hatfield, UK \\ Email: belabbas.belkacem@univ-tiaret.dz
}

\begin{abstract}
This paper proposes a hierarchical power management and energy control aimed at improving the reliability and efficiency of electric power generation from a wind farm connected to the grid. The Wind Farm (WF) consists of three Wind Energy Conversion Systems (WECS) each consisting of a wind turbine, a Double-Feed Induction Generator (DFIG) and five-level power converters. The first control layer includes a Maximum Power Point Tracking (MPPT) algorithm to extract the maximum power from the wind energy source based on an optimal torque control strategy. The real and reactive power flow from the WECS to the grid is controlled with a non-linear backstepping controller based on Lyapunov stability theory. Finally, a DC bus voltage controller with clamping bridge is employed to ensure the stability of the DC bus voltage and to compensate for transient disturbances caused by load fluctuations. The second layer of control ensures coordination between the wind farm, the power grid and the load to ensure a reliable and efficient power supply. The model of the grid-connected wind farm and the proposed control scheme are developed using MATLAB and Sim Power Systems Toolbox. A series of simulation scenarios are presented to evaluate the performance of the proposed control scheme under various operating conditions.
\end{abstract}

Keywords: Wind farm, energy management, MPPT, backstepping control, multilevel converters.

The ever-increasing energy consumption, the fluctuating cost of fossil fuels and the deterioration of the global environment have led to a growing interest in Renewable Energy Systems (RES) that have now become vital to our energy ecosystem. Compared to conventional power plants, RES are sustainable, smaller in size than conventional power plants and can be installed closer to the load centers [1].

The design of a RES generation plant is very important from an economic, environmental and energy quality point of view as well as from the production point of view [2].

Currently, wind and photovoltaic power generation are the most promising renewable energy technologies. However, these technologies are intermittent and depend heavily on weather conditions. Therefore, the variable nature of these RES needs be partially resolved for the whole system to become more reliable and economical [3].

Wind energy is relatively clean and sustainable and has become one of the most promising energy resources worldwide. There has been an unprecedented development of wind energy technology over the last decade which has led to a considerable reduction in the cost of electricity generated from wind energy 
1 [4]. Typically, a WECS is composed of a wind turbine, a gearbox, a generator, a power converter, a

2 transformer and a grid. Currently, the majority of wind turbine systems operate at a variable speed in order

3 to increase the energy efficiency and improve the quality of electrical energy produced compared to fixed

4 speed wind turbines [5]. The WECS considered in this paper is based on the variable-speed DFIG. The

5 main advantage of using this type of machine is the ability to control the powers generated around an

6 operating point.

7 The amount of power that can be captured from a wind turbine depends on several parameters including 8 the wind turbine characteristics and wind variability, which depends of on the geographical location. MPPT

9 algorithms are designed to search for the optimum operating point that allows the wind turbine to extract 10 the maximum power from the available wind energy [6]. Several MPPT control strategies have been 11 proposed in the literature [7]-[14]. The MPPT used in this work is based on the Tip Speed Ratio (TSR) 12 control, which regulates the rotor speed, while keeping the TSR at its optimum value to capture the 13 maximum wind power. This method requires an accurate knowledge of the wind turbine parameters and 14 measurement of the wind speed in order to determine the required generator's speed to extract the maximum 15 power.

The control of the DFIG has been the subject of extensive research. Field Oriented Control (FOC) is the most popular control technique which aims to decouple the active and reactive powers of the DFIG through the orientation of the stator flux along the d-axis of Park frame. In this context, the Direct Control of Power (DCP) is a commonly used method to regulate the two powers because of its simplicity and ease of implementation. However, because this control is characterized by a single control loop of power, it is difficult to evaluate the rotor current in the DFIG. In this paper, the Indirect Control of Power (ICP) is used, which consists of two loops, an internal loop to control the rotor current and the external loop to control the two powers [15].

Several control strategies have been proposed in the literature to control the two loops of powers and rotor currents. Conventional controllers such as Proportional-Integral (PI) are the most commonly used due to their simplicity. However, these controllers with conservative parameters may not give satisfactory performance under challenging operating conditions such as parameter variations of the DFIG [16].

Robust nonlinear controllers based on Lyapunov stability theory have been proposed in the literature to improve the performance of the DFIG under challenging operating conditions. Among these, Backstepping Control (BSC) which is used in this work to control the power and rotor current of the DFIG [17], [18].

Different topologies of power converters have been proposed for power conditioning in WECS applications. Multilevel converters, especially the NPC topology, are the most commonly used in the development of high-voltage, high-power wind farms [19]. These converters have many advantages such 
1 as improved output voltage waveform, reduced THD (Total Harmonic Distortion) of the voltage and current

2 as compared to conventional converters and reduced size of the output filter.

3 The main drawback of these converters is the balancing of the capacitor voltages in the DC bus. In the

4 literature, this problem has been solved a two loops control scheme. The most widely used control strategy

5 relies on two cascading control loops. The external loop controls the average value of the DC voltage by a

6 standard IP type regulator. For the internal loop, a Hysteresis type regulator is used to control the grid-side 7 currents.

8 In this study, we have used a five-level NPC converter. To control the difference between the two 9 voltages in each half-arm. A balancing bridge structure called a Clamping Bridge Circuit (CBC) was used 10 to provide the balance and stability of DC voltage for the five-level NPC converter.

11 For a reliable and efficient operation of the proposed grid-connected wind farm, it is necessary to 12 develop an Energy Management (EM) algorithm to ensure energy balance between demand on the one side 13 and wind farm generation and grid on the other side [20]. The EM should be able to handle all possible load 14 case scenarios and respond quickly to energy needs of the load. The role of the EM is also to maintain good 15 regulation of the DC link voltage and ensure stable operation under changing weather and fault conditions.

The main aim of this paper is to improve the quality of the energy generated by the wind farm integrated into the grid.

The rest of the paper is organized as follows: Section 2 presents a description and modeling for the different parts of a of WECS including the wind turbine, the DFIG and the five-level static converters. In Section 3, the proposed control schemes for the wind turbine, DFIG and five-level static converters are presented. The Energy Management of the proposed WECS system is discussed in Section 4. The simulation results and discussions are presented in Section 5. Finally, conclusions are given in Section 6.

\section{II. Modeling of the SCEE}

Fig. 1 shows the layout of the wind farm consisting of three of WECS of $7.5 \mathrm{~kW}$ each and connected to the low voltage side of the grid.

The simplified configuration and control scheme of the WECS is illustrated in Fig. 2. It consists of a wind

27 turbine with MPPT controller, a DFIG and two back-to-back five-level NPC converters, described as a set

28 of two voltage sources coupled through a DC-link. The Rotor Side Converter (RSC) is directly connected 29 to the rotor of DFIG, while the Grid Side Converter (GSC) is connected through an RL filter to the lowvoltage electric grid. 


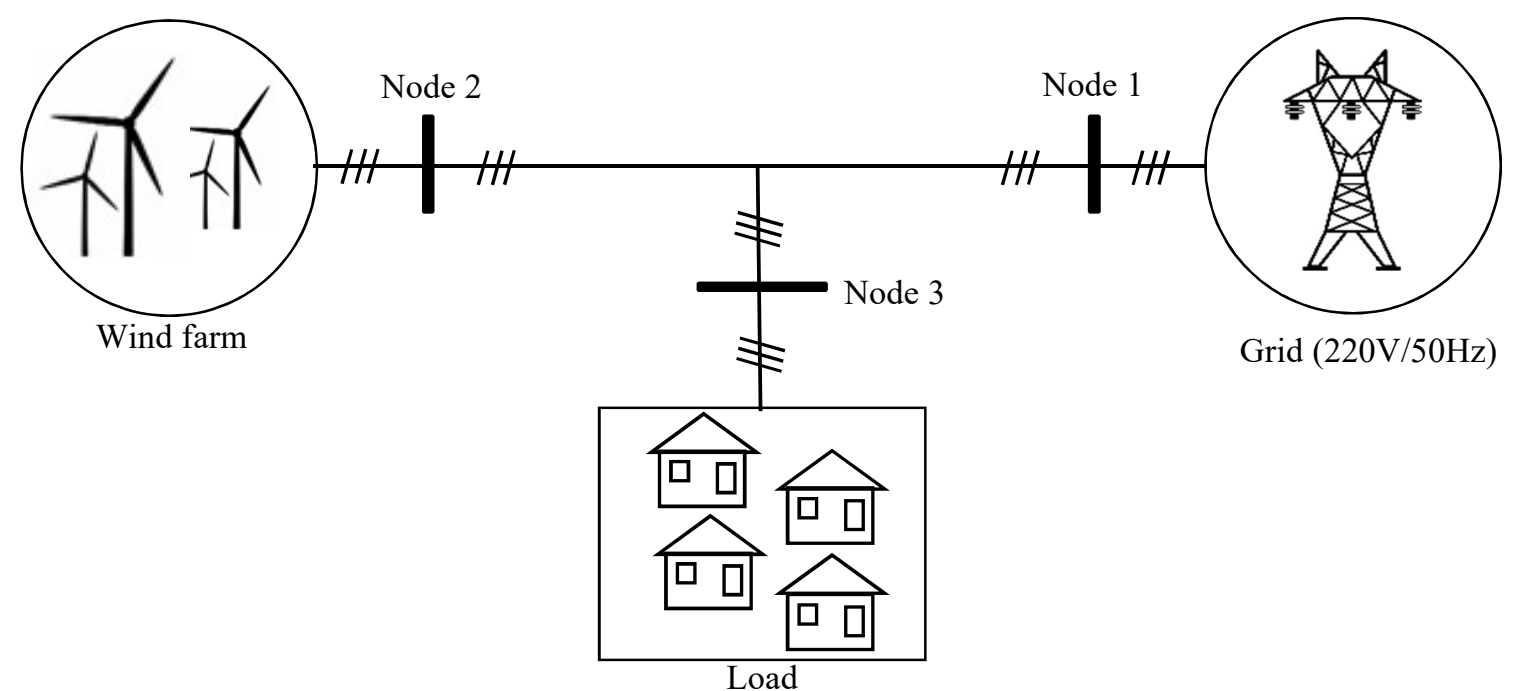

Fig. 1. Structure of the Wind Turbine Farm.

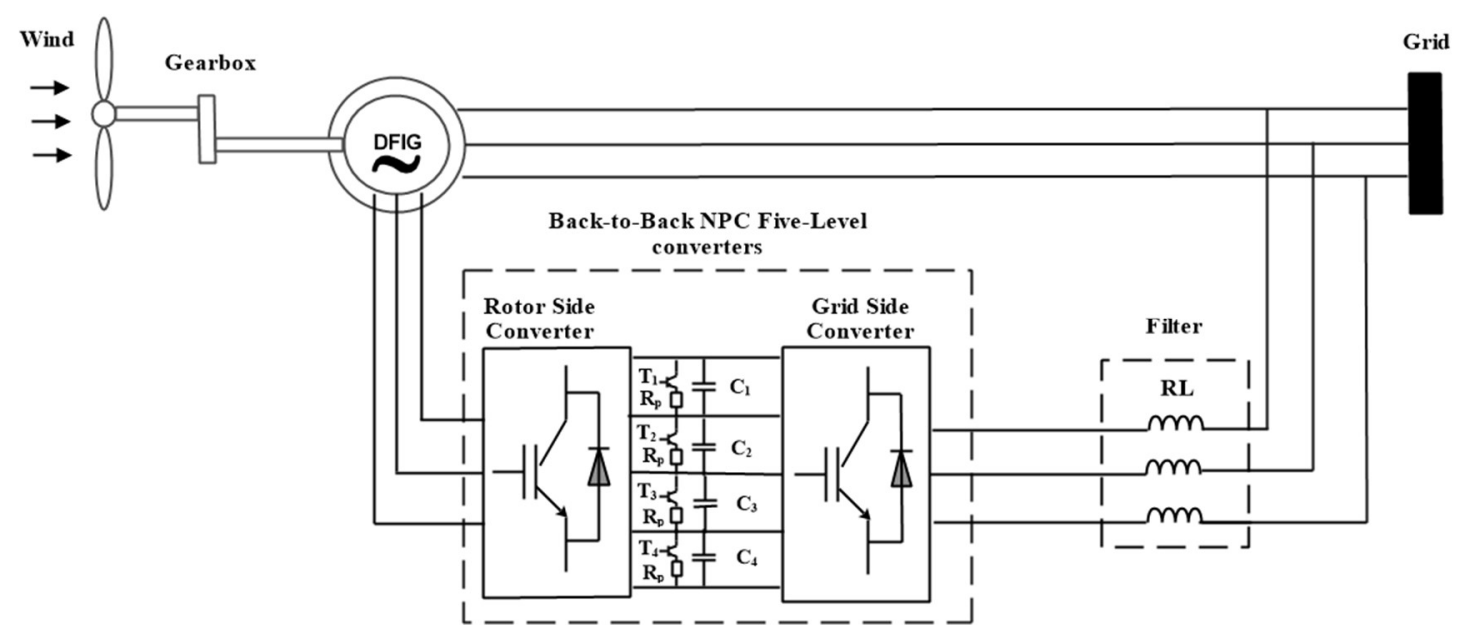

Fig. 2. Structure and control scheme of the WECS.

\section{II.1 Wind turbine model and characteristics}

15 The wind turbine converts the kinetic energy of the wind into aerodynamic power $P_{a}$. It expressed by 16 the following equation [5], [21]:

$$
P_{a}=\frac{1}{2} C_{p}(\lambda, \beta) \rho \pi R^{2} V^{3}
$$

$$
\lambda=\frac{R \Omega_{t}}{V}
$$
The aerodynamic torque is given by:

$$
\mathrm{T}_{a}=\frac{\mathrm{P}_{a}}{\Omega_{t}}
$$


The block diagram of the Wind Turbine (WT) model is illustrated in Fig. 3. The coupling of the shaft

2 between the wind turbine and the DFIG is via the gearbox $G$. The speed and torque of the generator are

3 given by:

$$
\Omega_{t}=\frac{\Omega_{m e c}}{G}
$$

$$
\mathrm{T}_{g}=\frac{\mathrm{T}_{a}}{G}
$$

6

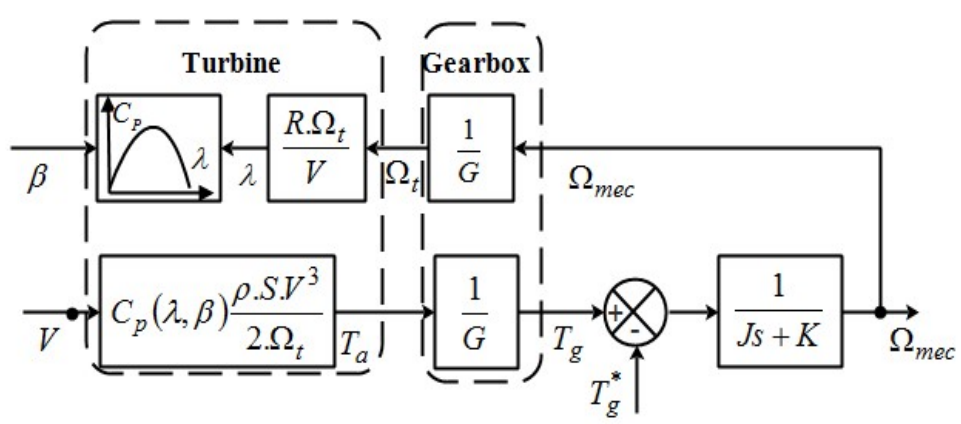

Fig. 3. Block diagram of the modeling of a Wind Turbine.

\section{II.2 Modelling of the DFIG} of voltages and flux linkages for the stator and rotor respectively [7]:

$$
\begin{gathered}
\left\{\begin{array}{l}
\mathrm{V}_{d s}=\mathrm{R}_{s} \mathrm{i}_{d s}+\mathrm{L}_{s} \frac{d \psi_{d s}}{d t}-\omega_{s} \psi_{q s} \\
\mathrm{~V}_{q s}=\mathrm{R}_{s} \mathrm{i}_{q s}+\mathrm{L}_{s} \frac{d \psi_{q s}}{d t}+\omega_{s} \psi_{d s} \\
\mathrm{~V}_{d r}=\mathrm{R}_{r} \mathrm{i}_{d r}+\mathrm{L}_{r} \frac{d \psi_{d r}}{d t}-\omega_{r} \psi_{q r} \\
\mathrm{~V}_{q r}=\mathrm{R}_{r} \mathrm{i}_{q r}+\mathrm{L}_{r} \frac{d \psi_{q r}}{d t}-\omega_{r} \psi_{d r}
\end{array}\right. \\
\begin{cases}\psi_{d s}=\mathrm{L}_{s} \mathrm{i}_{d s}+\mathrm{L}_{m} \mathrm{i}_{d r} \\
\psi_{q s}=\mathrm{L}_{s} \mathrm{i}_{q s}+\mathrm{L}_{m} \mathrm{i}_{q r} \\
\psi_{d r}=\mathrm{L}_{r} \mathrm{i}_{d r}+\mathrm{L}_{m} \mathrm{i}_{d s} \\
\psi_{q r}=\mathrm{L}_{r} \mathrm{i}_{q r}+\mathrm{L}_{m} \mathrm{i}_{q s}\end{cases}
\end{gathered}
$$

The classical DFIG model described in the Park reference frame given by the following set of equations

The electromagnetic torque is:

$$
T_{e m}=\frac{3}{2} \frac{P \mathrm{~L}_{m}}{\mathrm{~L}_{s}}\left(\psi_{q s} \mathrm{i}_{d r}-\psi_{d r} \mathrm{i}_{q r}\right)
$$


1 The active and reactive powers of the DFIG are expressed as:

2

$$
\left\{\begin{array}{l}
P_{s}=\mathrm{V}_{d s} \mathrm{i}_{d s}+\mathrm{V}_{q s} \mathrm{i}_{q s} \\
Q_{s}=\mathrm{V}_{q s} \mathrm{i}_{d s}-\mathrm{V}_{d s} \mathrm{i}_{q s}
\end{array}\right.
$$

\section{II.2.1 DFIG with Stator Field Orientation Strategy}

4

5

6

7

8

$$
\begin{aligned}
& \text { Applying the field-orientation strategy of the stator flux on the d-axis gives:[22], [23] } \\
& \left\{\begin{array}{l}
\psi_{d s}=\psi_{s} \\
\psi_{q s}=0
\end{array}\right. \\
& \left\{\begin{array}{l}
V_{d s}=0 \\
V_{q s}=V_{s} \approx \omega_{s} \psi_{s}
\end{array}\right. \\
& \left\{\begin{array}{c}
\psi_{s}=\mathrm{L}_{s} \mathrm{i}_{d s}+\mathrm{L}_{m} \mathrm{i}_{d r} \\
0=\mathrm{L}_{s} \mathrm{i}_{q s}+\mathrm{L}_{m} \mathrm{i}_{q r}
\end{array}\right. \\
& T_{e m}=-\frac{3}{2} \frac{P \mathrm{~L}_{m}}{\mathrm{~L}_{s}}\left(\psi_{d r} \mathrm{i}_{q r}\right)
\end{aligned}
$$

The equations relating the stator currents to the rotor currents are obtained as:

$$
\left\{\begin{array}{l}
\mathrm{i}_{d s}=\frac{\mathrm{V}_{s}}{\omega_{s} L_{s}}-\frac{\mathrm{L}_{m}}{L_{s}} \mathrm{i}_{d r} \\
\mathrm{i}_{d r}=-\frac{\mathrm{L}_{m}}{L_{s}} \mathrm{i}_{q r}
\end{array}\right.
$$

13 With:

14

$$
\left\{\begin{array}{l}
F_{e m d}=g \omega_{s} \mathrm{~L}_{r} \sigma \mathrm{i}_{q r} \\
F_{e m q}=g \omega_{s} \mathrm{~L}_{r} \sigma \mathrm{i}_{d r}+g \frac{\mathrm{L}_{m} V_{s}}{L_{s}}
\end{array}\right.
$$

$$
\sigma=1-\frac{L_{m}^{2}}{\mathrm{~L}_{r} L_{s}}
$$

$$
\left\{\begin{array}{l}
\mathrm{V}_{d r}=\mathrm{R}_{r} \mathrm{i}_{d r}+\mathrm{L}_{r} \sigma \frac{d i_{d r}}{d t}-F_{e m d} \\
\mathrm{~V}_{q r}=\mathrm{R}_{r} \mathrm{i}_{q r}+\mathrm{L}_{r} \sigma \frac{d i_{q r}}{d t}+F_{e m q}
\end{array}\right.
$$


Finally, equation (9) becomes:

$$
\left\{\begin{array}{l}
P_{s}=-\frac{\mathrm{V}_{s} \mathrm{~L}_{m}}{L_{s}} \mathrm{i}_{q r} \\
Q_{s}=-\frac{\mathrm{V}_{s} \mathrm{~L}_{m}}{L_{s}} \mathrm{i}_{d r}+\frac{V_{s}^{2}}{\omega_{s} L_{s}}
\end{array}\right.
$$

\section{II.2.2 Five-Level NPC Converter}

4 The topology of the five-level NPC converter is shown in Fig. 4. For the operation of this converter, seven configurations are used. Table 1 presents the magnitudes of the electrical quantities that characterize each configuration (with $M$ representing the reference point of the potentials and $V_{K M}(K=A, B$ or $C)$ as the potential of node $K$ of $\operatorname{arm} k(k=A, B$ or $C))$. The DC voltage sources $V_{c 1}, V_{c 2}, V_{c 3}$ and $V_{c 4}$ are provided by the rectifier (GSC). The modeling of the five-level NPC converter is discussed in more details in [24].

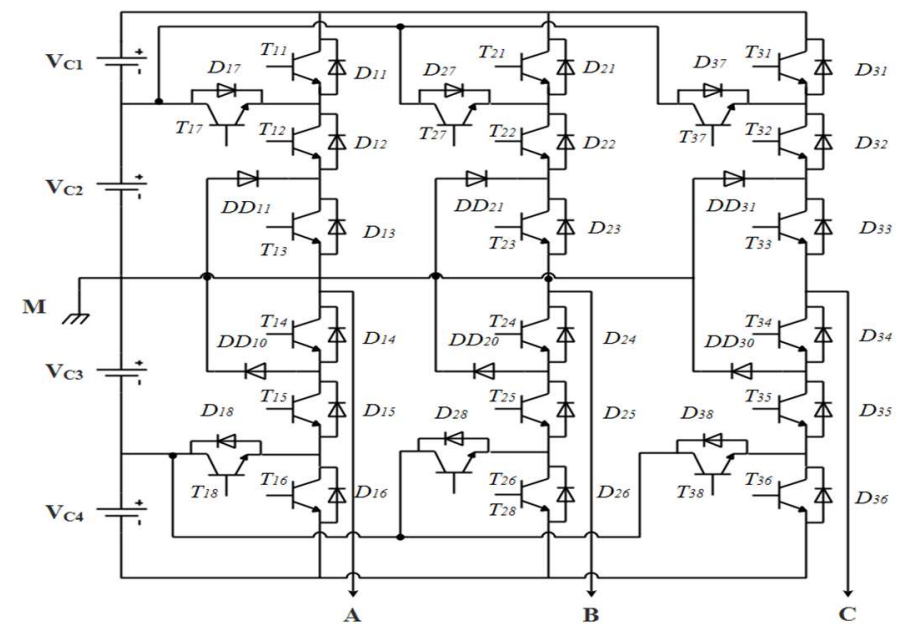

Fig. 4. Topology of the five-level NPC converter.

Table. 1. Electrical magnitudes of each configuration of arm $k$.

\begin{tabular}{cl}
\hline Configurations & Electric quantities \\
\hline$E_{0}$ & $i_{k}=0$ \\
$E_{1}$ & $V_{K M}=U_{C 1}+U_{C 2}$ \\
$E_{2}$ & $V_{K M}=U_{C 1}$ \\
$E_{3}$ & $V_{K M}=0$ \\
$E_{4}$ & $V_{K M}=-U_{C 3}$ \\
$E_{5}$ & $V_{K M}=-U_{C 3}+U_{C 4}$ \\
$E_{6}$ & $V_{K M}=0$ \\
\hline
\end{tabular}




\section{III. CONTROL STRATEGIES}

2 This section provides a detailed description and the design steps of the different control strategies 3 employed in the WECS.

\section{$4 \quad$ III.1 MPPT with speed control}

5 The goal of the MPPT strategy is to extract the maximum power from the wind. The TSR (Tip Speed 6 Ratio) is the most frequently used method for MPPT. Fig. 5 shows that the optimum turbine speed compared 7 with the actual value and the difference is then fed into PI controller to obtain the reference for the 8 Electromagnetic torque.

9 The optimal turbine speed achieved when TSR remains at its optimal value is given by:

$$
\Omega_{t}^{*}=\frac{\lambda_{o p t} V}{R}
$$

Under these conditions, the maximum power is:

$$
P_{o p t}=\frac{C_{\text {pmax }}}{\lambda_{o p t}^{3}} \frac{\rho \pi R^{5}}{2} \frac{\Omega_{m e c}^{3}}{G^{3}} \Omega
$$

23

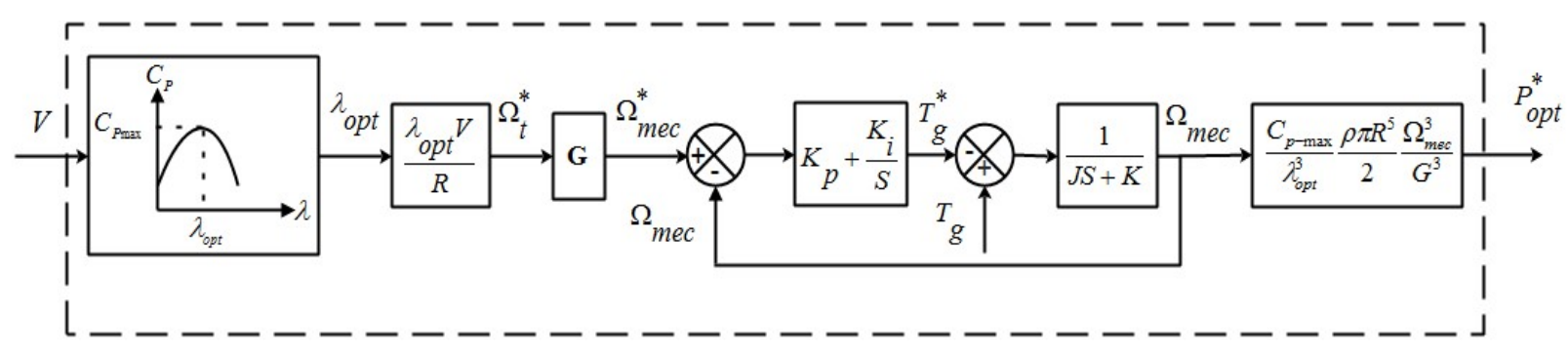

Fig. 5. MPPT with speed control.

\section{III.2 Nonlinear control design for DFIG}

In this section, a nonlinear Backstepping control laws for the rotor currents and DFIG power are presented:

The control by Back-Stepping is tries to find a stabilizing control for nonlinear systems closed loop, this stability ensured basing on Lyapunov theory. Its design procedure applied for a model of the DFIG include the following steps:

Step 1: Active and reactive power control

Defining the active and reactive power errors as:

$$
\left\{\begin{array}{l}
e_{1}=P_{s}^{*}-P_{s} \\
e_{3}=Q_{s}^{*}-Q_{s}
\end{array}\right.
$$


1 The derivative of the error is:

$$
\left\{\begin{array}{c}
\dot{e}_{1}=\dot{P}_{s}^{*}-\dot{P}_{s} \\
\dot{e}_{3}=\dot{Q}_{s}^{*}-\dot{Q}_{s}
\end{array}\right.
$$

3 The first Lyapunov function can be chosen as:

$$
V_{1}=\frac{1}{2} e_{1}^{2}+\frac{1}{2} e_{3}^{2}
$$

5 The derivative of the function $V_{1}$ expressed as:

$$
\dot{V}_{1}=e_{1} \dot{e}_{1}+e_{3} \dot{e}_{3}
$$

$7 \quad$ Which can be rewritten as:

$$
\dot{V}_{1}=-K_{1} e_{1}^{2}-K_{3} e_{3}^{2}
$$

9 To ensure that the derivative of $\dot{V}_{1}$ is negative, the constants $K_{1}$ and $K_{3}$ should be positive. Equation (20) can be rewritten as follows:

$$
\left\{\begin{array}{l}
\dot{e}_{1}=\left(\dot{P}_{s}^{*}+\frac{\mathrm{V}_{s} \mathrm{~L}_{m}}{L_{s}} \dot{\mathrm{i}}_{q r}\right)=-K_{1} e_{1} \\
\dot{e}_{3}=\left(\dot{Q}_{s}^{*}+\frac{\mathrm{V}_{s} \mathrm{~L}_{m}}{L_{s}} \dot{\mathrm{i}}_{d r}\right)=-K_{3} e_{3}
\end{array}\right.
$$

12 Finally, the direct and quadratic of rotor currents of the DFIG are chosen as:

$$
\left\{\begin{array}{l}
\dot{\mathrm{i}}_{d r}^{*}=\frac{\mathrm{L}_{s}}{\mathrm{~V}_{s} \mathrm{~L}_{m}}\left(-\dot{Q}_{s}^{*}-K_{3} e_{3}\right) \\
\dot{\mathrm{i}}_{q r}^{*}=\frac{\mathrm{L}_{s}}{\mathrm{~V}_{s} \mathrm{~L}_{m}}\left(-\dot{P}_{s}^{*}-K_{1} e_{1}\right)
\end{array}\right.
$$

14 Step 2: Rotor currents control

15 Defining the rotor currents errors as:

16

$$
\left\{\begin{array}{l}
e_{2}=i_{q r}^{*}-i_{q r} \\
e_{4}=i_{d r}^{*}-i_{d r}
\end{array}\right.
$$

17 The derivative of the error is as:

$$
\left\{\begin{array}{l}
\dot{e}_{2}=\dot{i}_{q r}^{*}-\dot{i}_{q r} \\
\dot{e}_{4}=\dot{i}_{d r}^{*}-\dot{i}_{d r}
\end{array}\right.
$$

With: 


$$
\left\{\begin{array}{l}
\dot{\mathrm{i}}_{d r}=\frac{1}{\mathrm{~L}_{r} \sigma}\left(\mathrm{V}_{d r}-\mathrm{R}_{r} \mathrm{i}_{d r}\right) \\
\dot{\mathrm{i}}_{q r}=\frac{1}{\mathrm{~L}_{r} \sigma}\left(\mathrm{V}_{q r}-\mathrm{R}_{r} \mathrm{i}_{q r}\right)
\end{array}\right.
$$

2 The second Lyapunov function can be chosen as:

$$
V_{2}=\frac{1}{2} e_{1}^{2}+\frac{1}{2} e_{2}^{2}+\frac{1}{2} e_{3}^{2}+\frac{1}{2} e_{4}^{2}
$$

4 The derivative of $V_{2}$ is:

$$
\dot{V}_{2}=e_{1} \dot{e}_{1}+e_{2} \dot{e}_{2}+e_{3} \dot{e}_{3}+e_{4} \dot{e}_{4}
$$

$6 \quad$ Which can rewrite as follows:

$$
\dot{V}_{2}=-K_{1} e_{1}^{2}-K_{2} e_{2}^{2}-K_{3} e_{3}^{2}-K_{4} e_{4}^{2}
$$

8 To ensure that the derivative of $\dot{V}_{2}$ is negative, the constants $K_{3}$ and $K_{4}$ should be positive. Equation (26) 9 can be rewritten as follows:

$$
\left\{\begin{array}{l}
\dot{e}_{2}=\frac{\mathrm{L}_{s}}{\mathrm{~V}_{s} \mathrm{~L}_{m}}\left(-\dot{P}_{s}^{*}-K_{1} e_{1}\right)-\frac{1}{\mathrm{~L}_{r} \sigma}\left(\mathrm{V}_{q r}-\mathrm{R}_{r} \mathrm{i}_{q r}\right)=-K_{2} e_{2} \\
\dot{e}_{4}=\frac{\mathrm{L}_{s}}{\mathrm{~V}_{s} \mathrm{~L}_{m}}\left(-\dot{Q}_{s}^{*}-K_{3} e_{3}\right)-\frac{1}{\mathrm{~L}_{r} \sigma}\left(\mathrm{V}_{d r}-\mathrm{R}_{r} \mathrm{i}_{d r}\right)=-K_{4} e_{4}
\end{array}\right.
$$

11 Finally, the direct and quadratic of rotor voltages of the DFIG are chosen as:

12

$$
\left\{\begin{array}{l}
V_{d r}^{*}=\mathrm{L}_{r} \sigma\left(\frac{\mathrm{L}_{s}}{\mathrm{~V}_{s} \mathrm{~L}_{m}}\left(-\dot{Q}_{s}^{*}-K_{3} e_{3}\right)+\frac{\mathrm{R}_{r}}{\mathrm{~L}_{r} \sigma} \mathrm{i}_{d r}+K_{4} e_{4}\right) \\
V_{q r}^{*}=\mathrm{L}_{r} \sigma\left(\frac{\mathrm{L}_{s}}{\mathrm{~V}_{s} \mathrm{~L}_{m}}\left(-\dot{P}_{s}^{*}-K_{1} e_{1}\right)+\frac{\mathrm{R}_{r}}{\mathrm{~L}_{r} \sigma} \mathrm{i}_{q r}+K_{2} e_{2}\right)
\end{array}\right.
$$

A block diagram of the BSC used in this section is illustrated in Fig. 6. 


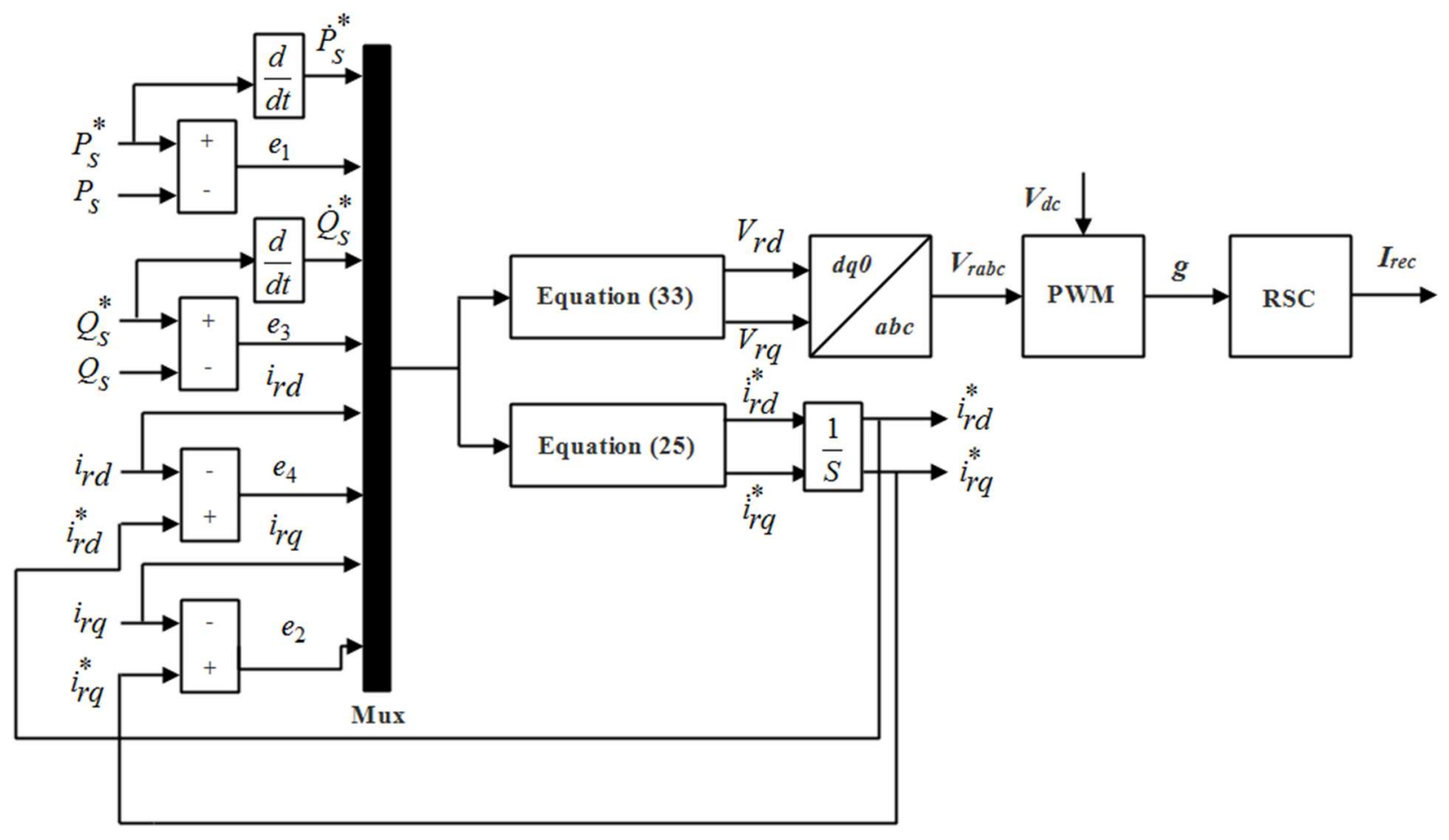

Fig. 6. Block diagram of the Back-Stepping Control (BSC).

\section{III.3 Control Strategy for the Five-Level NPC Converter}

The unbalance of the input voltages of the five-level inverter may potentially cause the floating-point problem. In addition, to have a perfect operation of the inverter with five levels, these four input voltages must be constant and equal.

To achieve this, these four voltages should be controlled via the three-phase current rectifier at five levels.

In the literature, the most widely used control strategy are based on two cascading control loops. The external loop controls the average value of the DC voltage by a standard IP type regulator. For the internal loop, a Hysteresis type regulator is used to control the grid-side currents.

The overall control structure of the NPC five-level converter on the grid side used in the wind-energy conversion chain is given in Fig. 7.

The block diagram of the DC bus voltage regulation is shown in Fig.8. The IP controllers are analogous to PI controllers except that proportional and integral actions are in series in contrast to PI controllers where these control actions are in parallel.

The external loop imposes the RMS value of the reference current of the grid $i_{\text {grid }}$.

$$
i_{\text {grid }}=\frac{2 \cdot V_{d c} \cdot i_{r e c}}{3 \cdot V_{\text {grid }}}
$$




$$
\left\{\begin{array}{l}
i_{\text {grid_1 }}=\sqrt{2} i_{\text {grid }} \sin (\omega t) \\
i_{\text {grid_2 }}=\sqrt{2} i_{\text {grid }} \sin \left(\omega t-\frac{2 \pi}{3}\right) \\
i_{\text {grid_3 }}=\sqrt{2} i_{\text {grid }} \sin \left(\omega t+\frac{2 \pi}{3}\right)
\end{array}\right.
$$

The quantities $\left(I_{c}, I_{d}, V_{d c}, I_{r e c}\right)$ are determined as follows:

$$
\left\{\begin{array}{c}
I_{C}=\frac{I_{C 1}+I_{C 2}+I_{C 3}+I_{C 4}}{4} \\
I_{d}=\frac{I_{d 1}+I_{d 2}-I_{d 3}-I_{d 4}}{4} \\
V_{d c}=\frac{V_{C 1}+V_{C 2}+V_{C 3}+V_{C 4}}{4} \\
I_{\text {rec }}=I_{C}+I_{d}
\end{array}\right.
$$

$4 \quad$ The balancing bridge structure called Clamping Bridge has been widely used in multilevel converters.

5 It consists of a transistor and a resistor $R_{p}$ in series, placed in parallel to the terminals of each capacity of

8 The mathematical model of the DC bus with the clamping bridge is obtained as follows.

$$
\left\{\begin{array}{l}
C_{1} \frac{d V_{c 1}}{d t}=I_{r e c 1}-I_{r 1}-I_{d 1} \\
C_{2} \frac{d V_{c 2}}{d t}=I_{r e c 1}+I_{r e c 2}-I_{r 2}-I_{d 1}-I_{d 2} \\
C_{3} \frac{d V_{c 3}}{d t}=-I_{r e c 3}-I_{r e}-I_{r 3}+I_{d 3}+I_{d 4} \\
C_{4} \frac{d V_{c 4}}{d t}=-I_{r e c 4}-I_{r 4}+I_{d 4}
\end{array}\right.
$$

10

With $I_{r i}=\frac{V_{c i}}{R_{p}} \cdot i=1,2,3,4$.

11 The algorithm which controls the clamping bridge compares the differences $\left(\Delta U_{12}\right)$ and $\left(\Delta U_{34}\right)$ in the

12 DC voltages of each stage against zero in real time. If the difference is not zero, the excess of energy will be dissipated through the resistance. The control algorithm of the clamping bridge is given as follows:

$$
\left\{\begin{array}{l}
\Delta V_{12}>0 \Rightarrow I_{r 1}=0 \& I_{r 2} \neq 0\left(T_{1}=0 \& T_{2}=1\right) \\
\Delta V_{12}<0 \Rightarrow I_{r 1} \neq 0 \& I_{r 2}=0\left(T_{1}=1 \& T_{2}=0\right) \\
\Delta V_{34}>0 \Rightarrow I_{r 3}=0 \& I_{r 4} \neq 0\left(T_{3}=0 \& T_{4}=1\right) \\
\Delta V_{34}<0 \Rightarrow I_{r 3} \neq 0 \& I_{r 4}=0\left(T_{2}=1 \& T_{4}=0\right)
\end{array}\right.
$$

With $\Delta V_{12}=V_{c 1}-V_{c 2} ; \Delta V_{34}=V_{c 3}-V_{c 4}$. 


\section{IV. Supervisory control system} current of the wind farm is less than 5.5\%. and the power requested by the load.

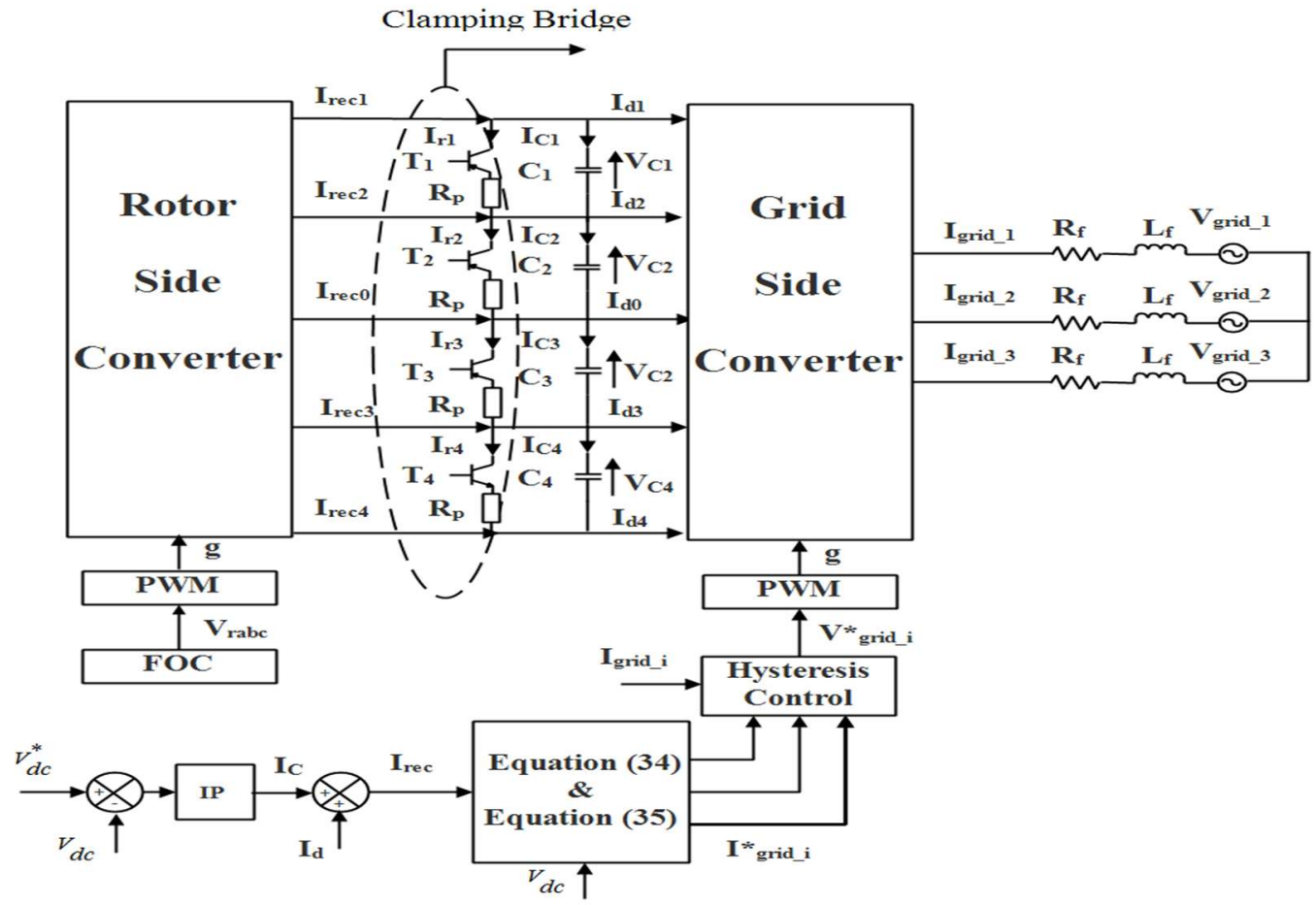

Fig. 7. Control structure of the five-level NPC converter.

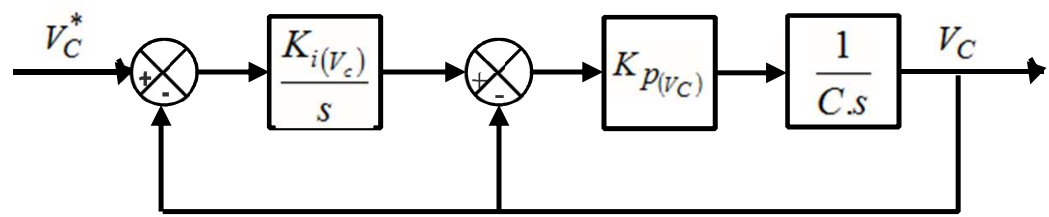

Fig. 8. DC bus voltage control loop.

Fig. 9 presents a flowchart for the Supervisory Control System (SCS) for the wind farm connected to the grid. The role of the SCS is to balance the power generated by the wind farm connected to the grid with the power required by the load for the various possible operating conditions.

In this study, the wind farm is connected to the grid and generates its optimal power if the following two conditions are satisfied: (i) The wind speed must be greater than a threshold speed. (ii) The THD of the

If both conditions are satisfied, a comparison is made between the power generated by the wind farm

If $P_{W F}<P_{L o a d}$, the electrical network intervenes and provides a power necessary for the load to ensure the energy balance between the load and the wind farm.

If $P_{W F}>P_{L o a d}$, the power difference between the wind farm and the load is injected into the grid.

If both conditions are not verified, then the grid will supply the total power required by the load. 


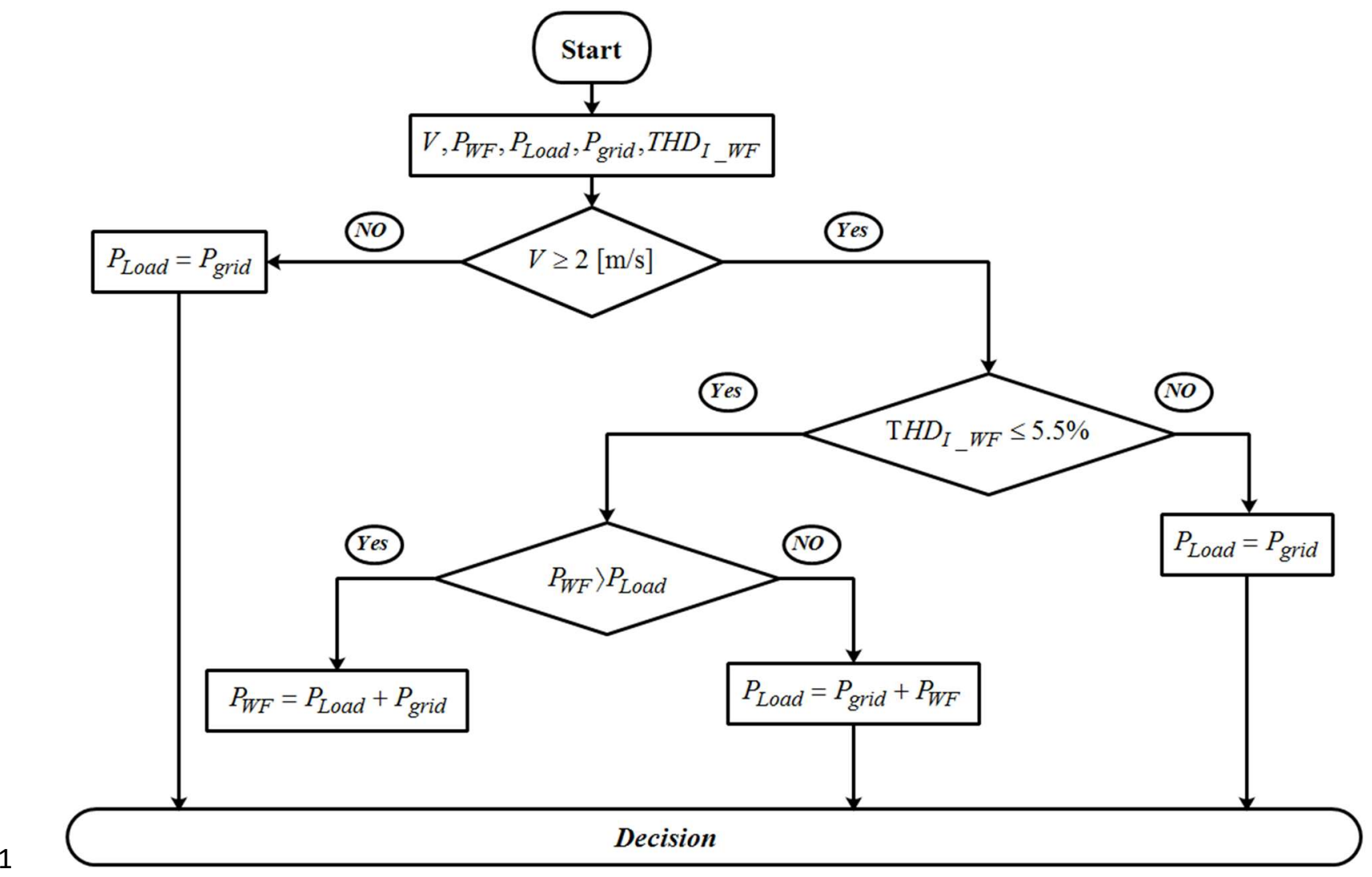

Fig. 9. Flowchart for the Supervisory Control System (SCS) for the wind farm connected to the grid.

\section{V. Simulation Results and Discussion}

4 The overall system of Fig. 1 was simulated in Matlab/Simulink environment with the parameters given

5 in the Appendix. This section presents a simulation study to evaluate the proposed control structure for the

6 grid-connected WF. To evaluate the performance of the WF connected to the power grid in terms of

7 stabilized, the quality of energy produced, four simulation scenarios under different operating conditions

8 have been studied and will be described in the following subsections.

$9 \quad$ Scenario 1: Constant load

10 The aim of this simulation is to demonstrate the performance of the wind farm connected to the power

11 grid in a healthy condition (i.e. without any faults) for a constant load of $20 \mathrm{~kW}$.

12 For this scenario of simulation, the wind speed profile used was recorded during a whole day in the City

13 of Tiaret (Algeria) with an average wind speed of approximately $6.5 \mathrm{~m} / \mathrm{s}$ as illustrated in Fig. 10 . We

14 considered a time scale of $0.1 \mathrm{sec}$ that corresponds to one hour.

15 Fig. 11 illustrates the responses of the mechanical speed with its reference. This figure shows that the 16 mechanical speed follows its reference with good performances (speed of response and accuracy). This 
1 result shows the effectiveness of the MPPT method based on the conventional PI controller to achieve the 2 desired speed of the wind turbine.

3

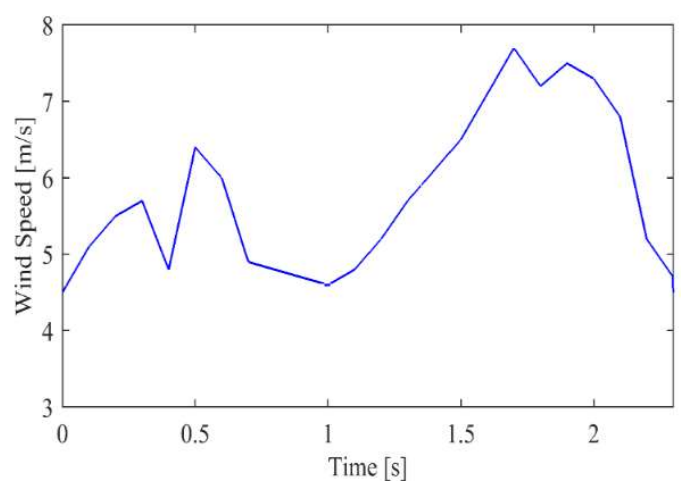

Fig. 10. Random of the wind.

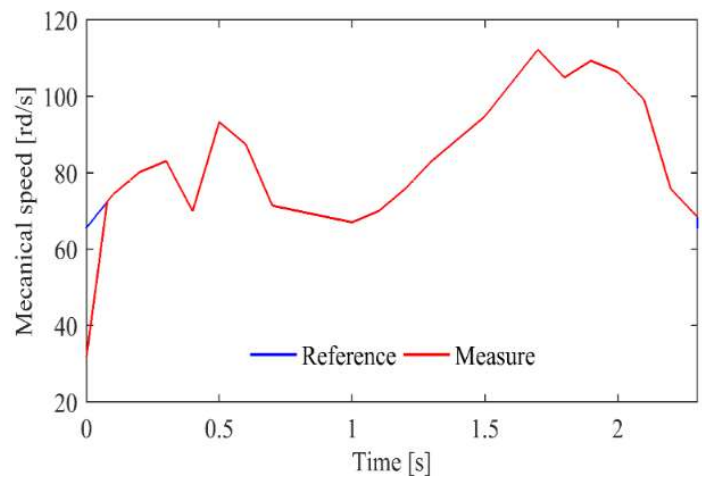

Fig. 11. Mechanical speed: reference (red) and actual (blue).

Fig.12 shows the power produced from the WF, the power delivered by the grid and the load power for phase 1. It is clear from this figure that the WF provides its optimal power to the load. The power grid also provides the energy required for the load to ensure the energy balance between the power demand by the load and the power generated by WF.

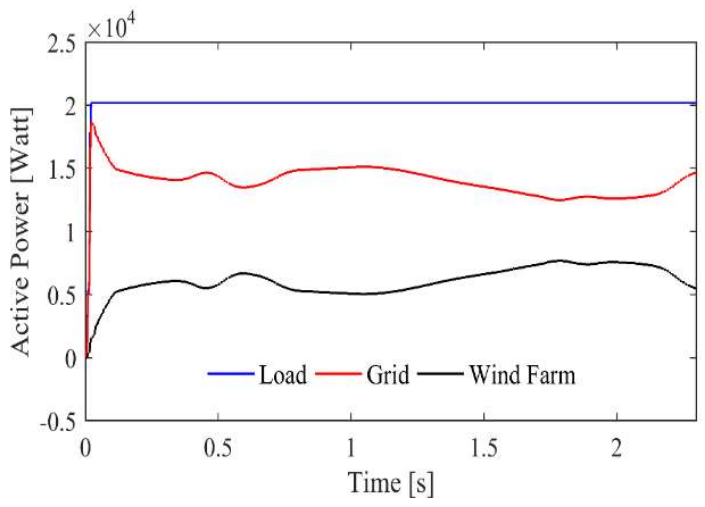

Fig. 12. Distribution of active power. 
Fig. 13 (a), (b) and (c) show the waveforms of the load, grid and wind farm currents respectively. From

2 these figures, the waveforms of the currents are sinusoidal, stable and that their frequencies are maintained 3 at $50 \mathrm{~Hz}$.
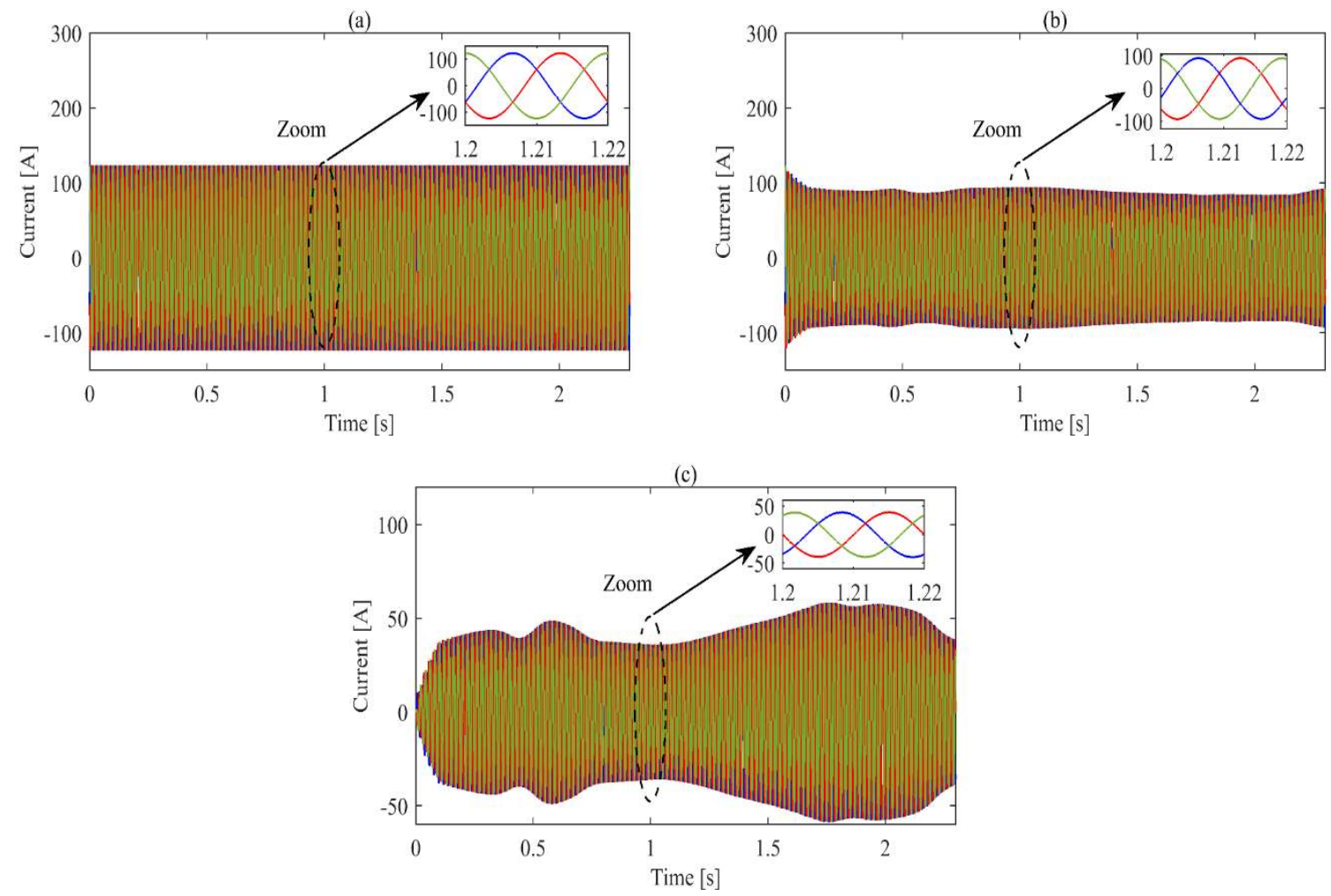

5

6

Fig. 13. Waveforms of currents: 11 an acceptable value.

(a) Load, (b) Grid and (c) wind farm.

According to IEEE standards, it is required that for the source of renewable energy to be connected to the electricity network, the THD of the current obtained must be less than 5\%. Fig. 14 (a), (b) and (c) show the analysis of the THD of the load currents, grid and the wind farm respectively.

It can be clearly observed that the THD of the wind farm current to be injected into the power grid has
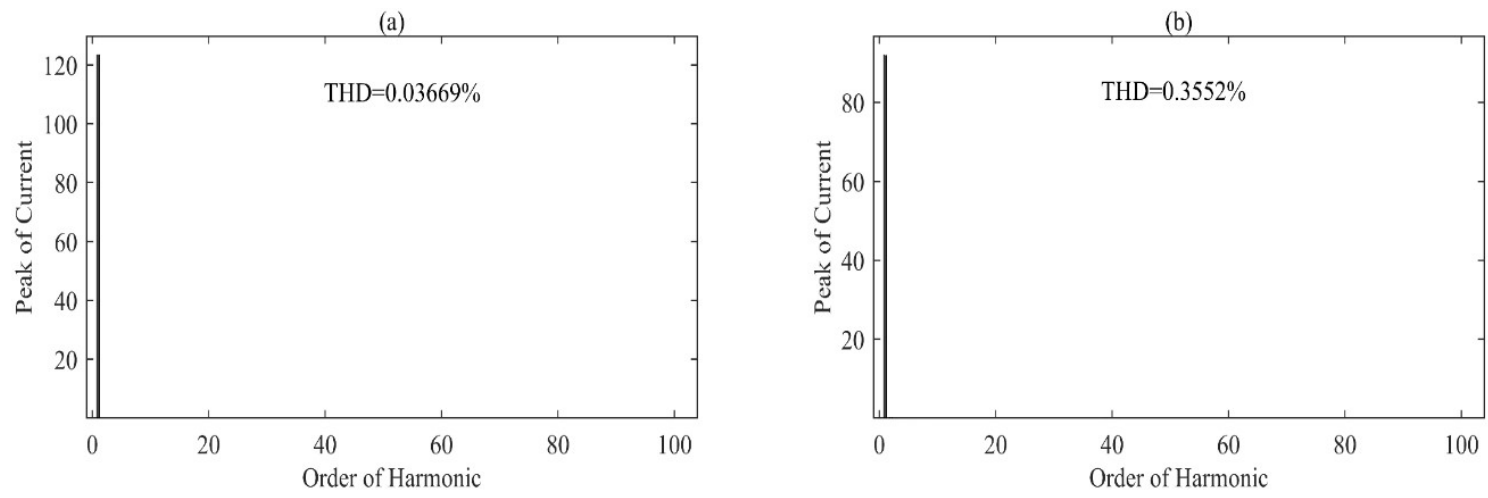


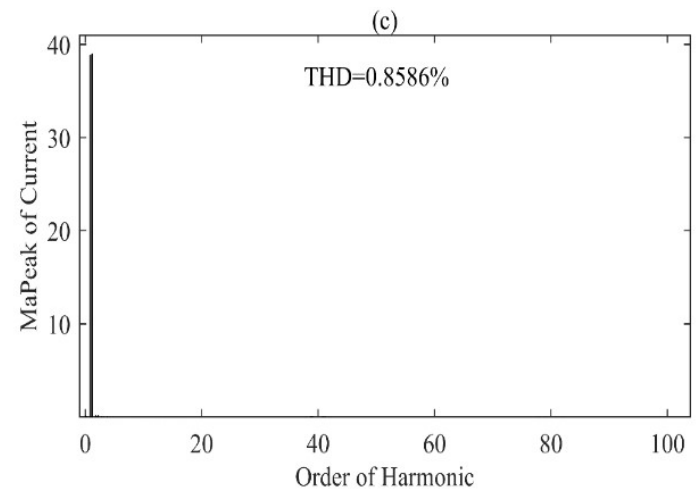

Fig. 14. THD of current measurement for: (a) Load, (b) Grid, (c) Farm wind.

These results demonstrate that the quality of energy produced by the wind farm is improved because of the use of multi-level converters and the efficiency of the integration of a RES into the grid.

Scenario 2: Balanced and variable load

This scenario allowed us to study the performance of the WF for a balanced variable load. This study will be examined for small variations in wind speed and for large wind speeds fluctuations.

The load considered in this scenario corresponds to the average daily consumption of a district consisting of 1000 dwellings in the city of Tiaret (Algeria).

\section{A. Variable wind speeds}

The load power distribution, the grid, and the WF are illustrated in Fig. 15. For this scenario, we considered the same wind speed profile as that of Fig. 10.

Depending on the wind profile, the control and monitoring system allowed the WF to generate its optimum power at any time as long as the wind speed is in a desired operating range and without compromising the safety of the system.

According to the optimal power generated by the WF and the power demanded by the load. The electricity grid must always follow the variation of the load to increase or reduce its production in order to ensure at any time the energy stability between the production sources and the load.

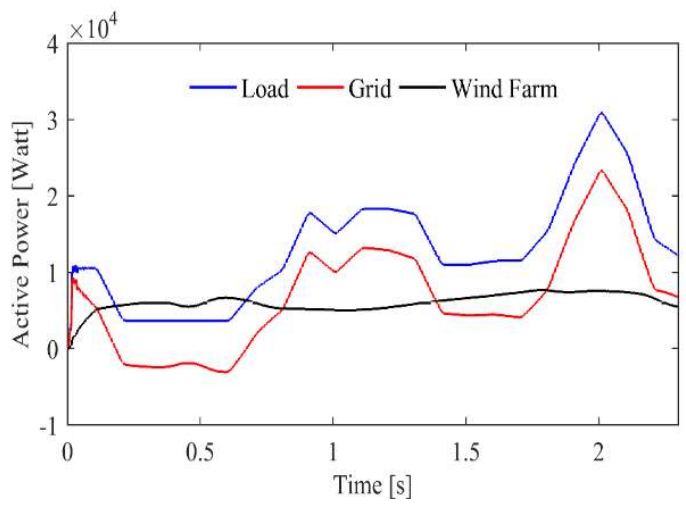

Fig. 157. Distribution of active power. 


\section{B. Large variations in wind speeds}

The wind speed profile considered in this simulation is shown in Fig. 16.a. Fig. 16.b shows the optimal power generated by the WF for phase 1. It can be observed that the profile of the power has the same trend 4 as the wind profile which indicates that the WF.

(a)

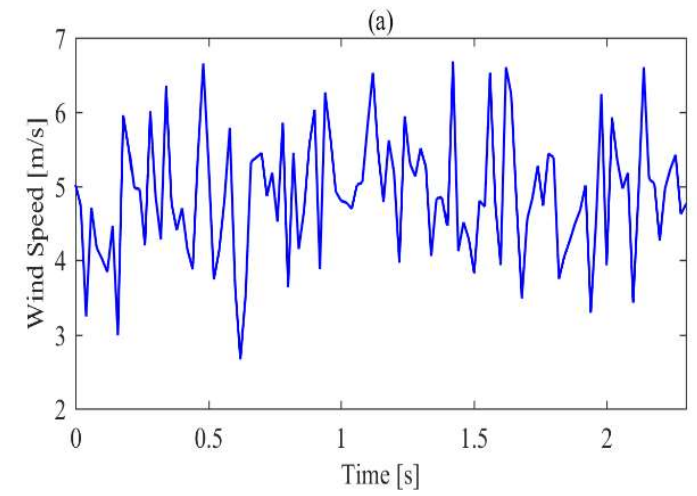

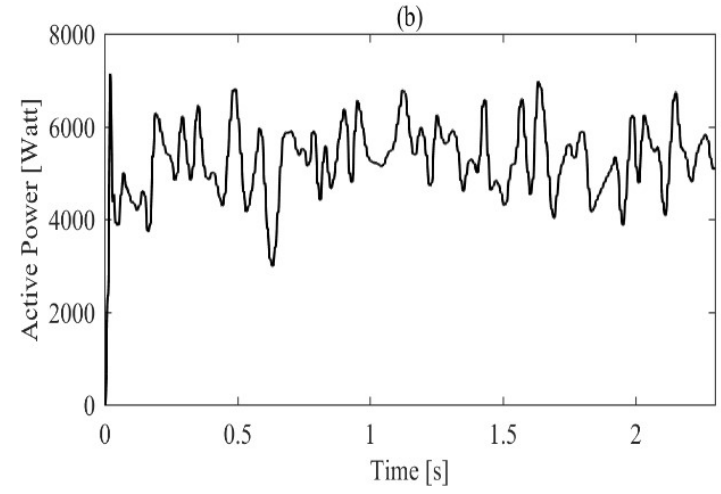

5

Fig.16. (a) Random of the wind. (b) Active power of WT (Phase 1).

Figs. 17 (a) and (b) show the power coefficient $\left(C_{p}\right)$ and tip speed ratio $(\lambda)$ curves respectively. Note that the $C_{p}$ and $\lambda$ work with these maximum values. They are slightly influenced by variations of the wind speed, but they seek at every moment to keep their maximum values in order to extract the maximum from the wind energy.

The power coefficient reference and tip speed ratio considered in this simulation study are set to their nominal values (i.e. $\left.C_{p}=0.48, \lambda=8.1\right)$ for a fixed setting angle $(\beta=0)$.

For safety, if the wind speed becomes too high or when there is turbulence, which can damage the wind turbine, the SCS intervenes and stops the wind system operation until the wind speed decreases again.
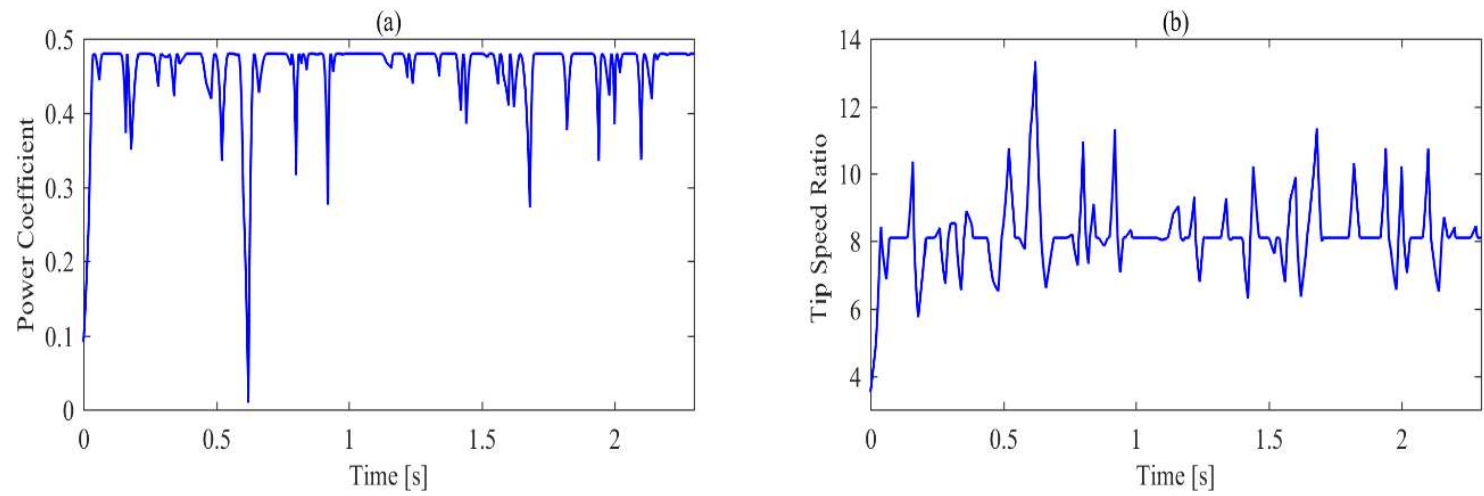

Fig.17. (a) Power coefficient, (b) Tip speed ratio (Phase 1).

The active power required by the load and those generated by the power grid and WF are illustrated are plotted in Fig. 18 which clearly shows that the power generated by the WF changes with the variation of the wind speed (Fig. 16.a). The power grid must react quickly to ensure a balance between the power demanded and the power generated. 


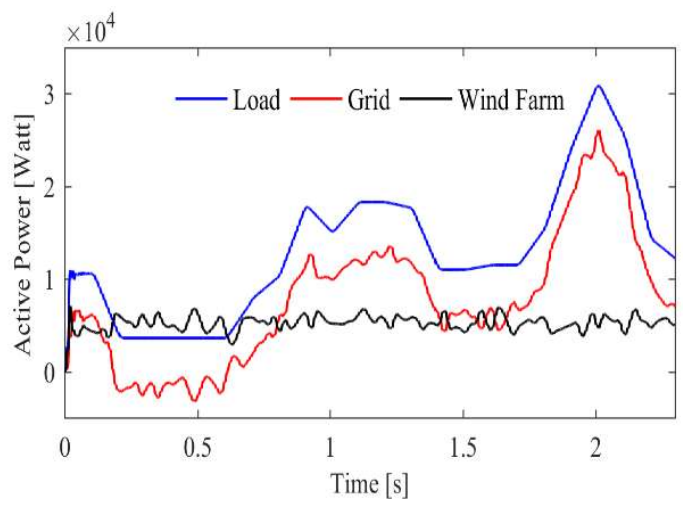

Fig.18. Distribution of active power.

3 Fig. 19 shows the response of the DC voltage which follows perfectly its reference. Also, the DC voltage $4 \quad$ is neither affected by the load variation nor by the wind speed.

$7 \quad$ Scenario 3: Variable unbalanced loads

8 When three load impedances are not equal, the phasor sums are not zero, and the load is therefore 9 unbalanced. The unbalance occurs when an open or short circuit appears in one or two phases at the load.

10 In this study, only one unbalanced load with a short circuit that appears in phase 1 is considered (Fig.

1120 ) between the two instants $t=1.25 \mathrm{~s}$ and $t=1.27 \mathrm{~s}$ with a balanced power source.

12 From Fig. 21, it is found that the system will be unbalanced following the appearance of the short-circuit.

13 But the system returns to its equilibrium state when the short-circuit is cleared.

14 As shown in Fig. 22, the DC voltage is not affected by the unbalanced load. These results confirm the 15 stability and good performance of WF connected to the power grid. 
1

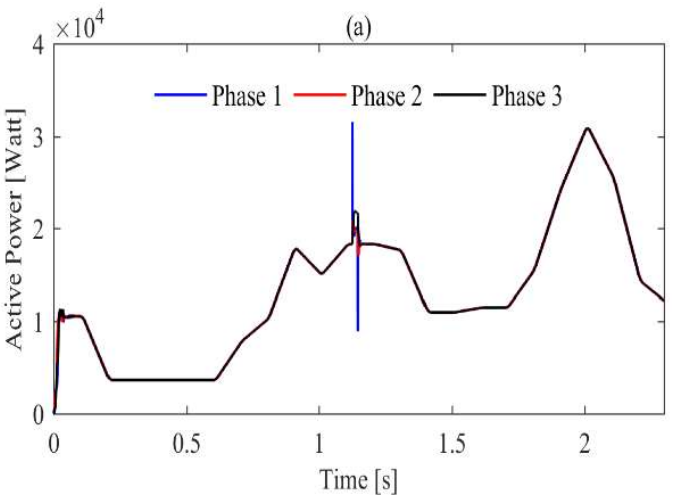

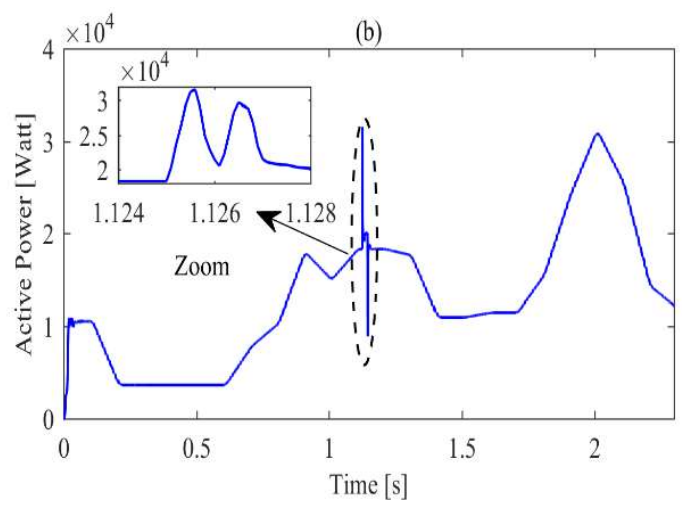

Fig. 20. (a) Three phases of Load, (b) One phase of Load.

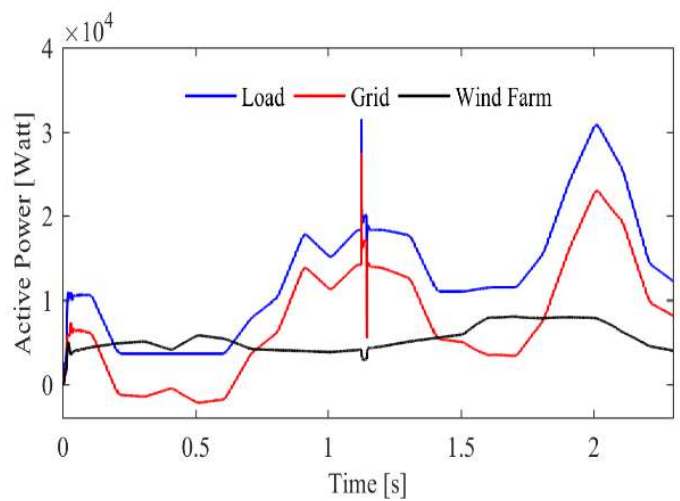

Fig. 21. Distribution of active power.

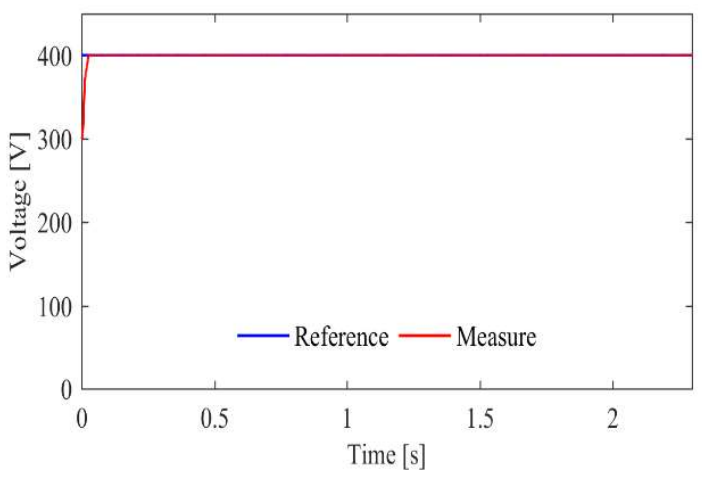

Fig. 22. DC voltage.

$7 \quad$ Scenario 4: Variable load with three-phase short circuit fault

8 The purpose of this scenario is to illustrate the dynamic behavior of a RES connected to the power grid, 9 and its impact on the stability of the system during a three-phase short-circuit fault. The three-phase short10 circuit fault is applied between the two instants $t=1.25 \mathrm{~s}$ and $t=1.27 \mathrm{~s}$. The distribution of the active

11 powers of the load, the power grid and the wind farm are shown in Fig. 23. It can be noted that these powers 12 went through three different regimes namely: 
Regime 1: the system is simulated before the occurrence of a fault during the interval $t=\left[\begin{array}{ll}0 & 1.25\end{array} \mathrm{~s}\right.$,

2 it is clear that the electricity grid and the wind farm fully ensure the generation of the power to the load to

3 ensure the stability between the required power and the power generated.

4 Regime 2: between $t=[1.251 .27] \mathrm{s}$, during the short-circuit fault. In this case, the RES connected to

5 the electrical network becomes unstable and has a transient state and an imbalance between the powers 6 generated and the requested one.

7 Regime 3: between $t=\left[\begin{array}{ll}1.27 & 2.3\end{array}\right] \mathrm{s}$, after the cancellation of the short-circuit fault, the RES connected 8 to the electrical network intervenes quickly to restore the balance of the power flow.

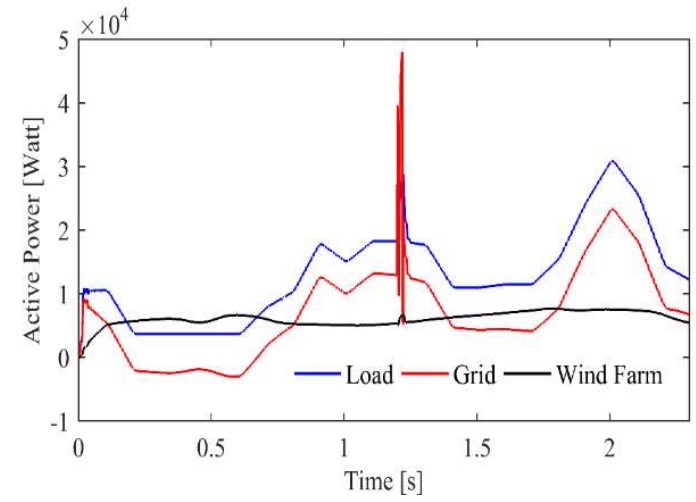

Fig. 23. Distribution of active power.

We notice the stability of the DC voltage (Fig. 24) before, during and after the cancellation of the short circuit. These results confirm the stability and good performance of WF connected to the power grid.

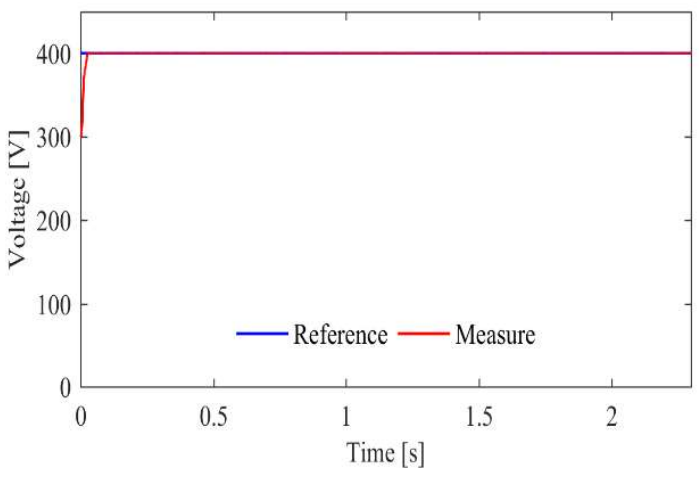

Fig. 24. DC voltage.

These results show the efficiency and the good performance of a RES after the cancellation of short circuit fault, because it produces the same power before and after this fault.

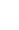

0


Scenario 5: Super- and sub-synchronous operation of DFIG

For this scenario, we are interested in studying the performance of the system when the DFIG operates

3 in the super- or sub-synchronous modes.

$4 \quad$ Another benefit of using the DFIG in the wind energy conversion system is that when the mechanical

5 speed exceeds the speed of synchronism (super-synchronous), the rotor circuit of DFIG generates a power

$6 \quad\left(P_{r}=g \cdot P_{s}\right)$ which will be associated with the stator power $\left(P_{s}\right)$ to be transferred to the load with total

7 power $\left(P_{T}=(1+g) \cdot P_{S}\right)$.

From Figs. 25 (a) and (b) which represent the wind speed and mechanical speed waveforms, it ca be observed that the mechanical speed exceeds the speed of synchronism if the wind speed assumes values above $11 \mathrm{~m} / \mathrm{s}$.

A close look at the mechanical speed response of Fig. 25 (b) shows that the DFIG operates in the supersynchronous mode and its power generated by phase 1 exceeds its rated power up to $t=1.5 \mathrm{~s}$ (Fig. 26 (a)).

When the wind speed is less than $11 \mathrm{~m} / \mathrm{s}$, the DFIG operates in the sub-synchronous mode because the mechanical speed is lower than the speed of synchronism. With the change of DFIG operating mode, it can be seen from Fig. 26 (b) that the system studied is stable and that the power demanded by the load is provided by the power grid and the WF. This scenario clearly demonstrates the effectiveness of the proposed control scheme when the DFIG-based WECS is operating in the super- or sub-synchronous mode.

18

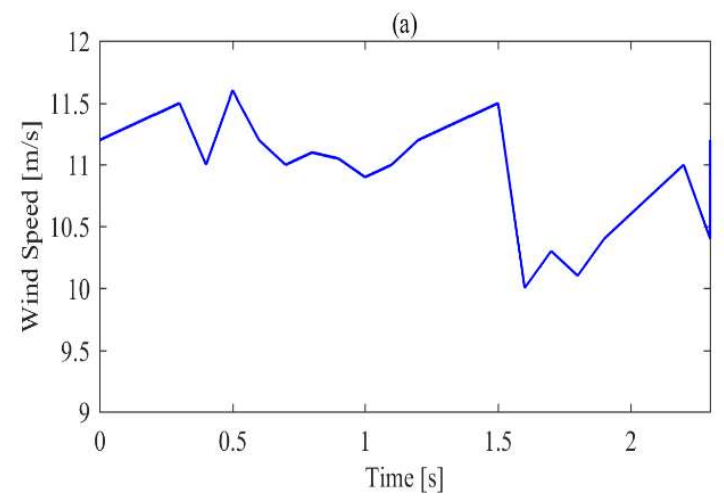

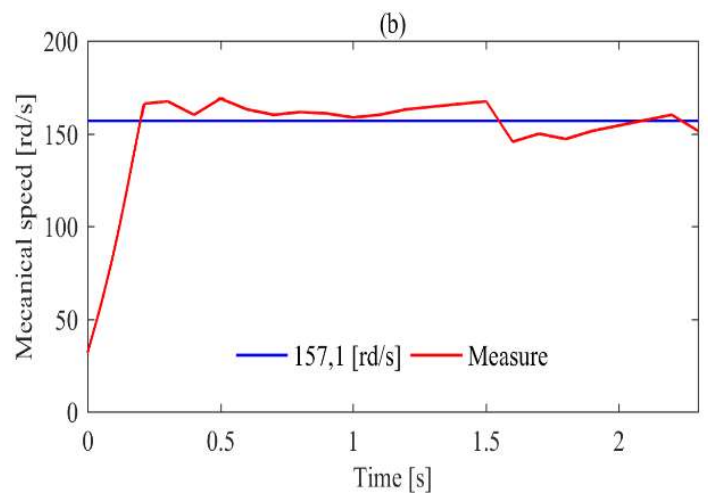

19

Fig. 25. (a) Wind speed, (b) Mechanical speed.
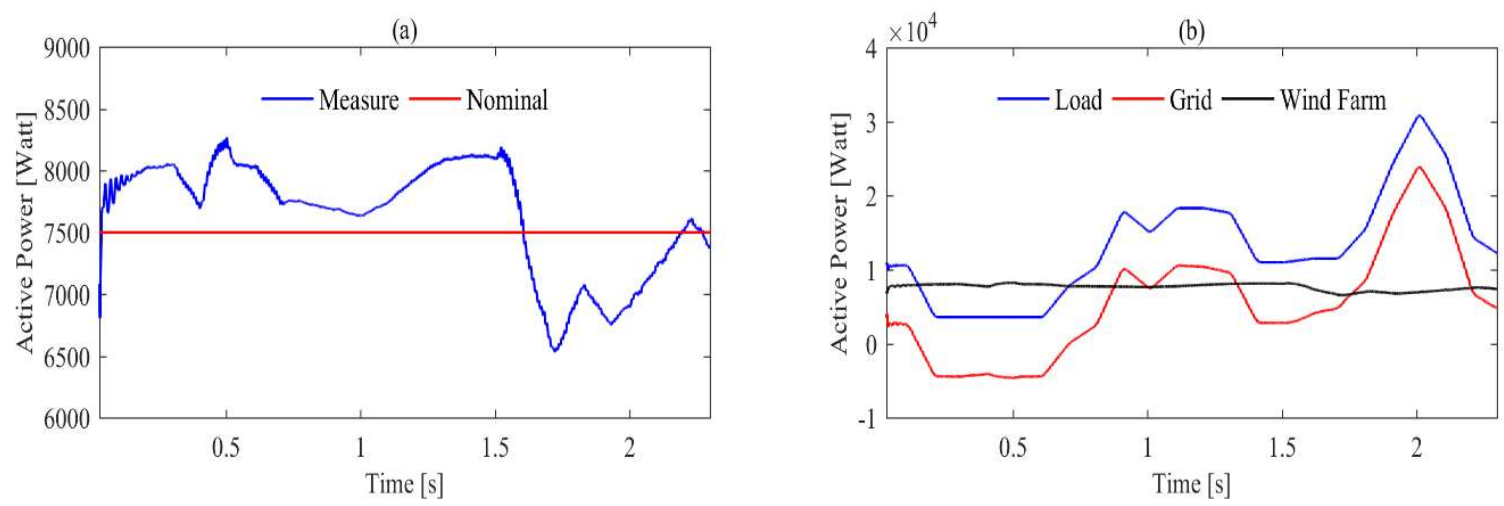
Fig. 26. (a) Power of WF, (b) Distribution of active power.

\section{VI. Conclusion}

3 This paper focused on the design of a hierarchical management and energy control from Wind Farm

4 (WF) connected to the grid to improve the reliability and efficiency of power generation. The WF consist

5 of three WECS based on a DFIG using the five-level converter topology to improve the quality of energy

6 produced by the WF. In this study, a strategy of Backstepping control has been proposed to control and

7 ensure the power generated by the WECS to enhance the performance of the WF.

8 The qualitative analysis is performed through a series of simulations to demonstrate the performance of

9 the WF connected to the power grid. Quantitative results show that the proposed wind energy conversion 10 system provides better performance as energy produced. Also, this system remains stable and efficient 11 under difficult operating conditions.

12 Appendix: Parameters of the Model.

Table. 2. Turbine parameter

\begin{tabular}{c|c|c}
\hline $\mathrm{P}_{\mathrm{n}, \text { tur }}$ & $\mathrm{KW}$ & 10 \\
\hline $\mathrm{R}$ & $\mathrm{m}$ & 3 \\
\hline $\mathrm{G}$ & & 5.4 \\
\hline $\mathrm{J}_{\mathrm{t}}$ & $\mathrm{Kg} \cdot \mathrm{m}^{2}$ & 0.042 \\
\hline $\mathrm{K}_{\mathrm{t}}$ & $\mathrm{N} \cdot \mathrm{m} \cdot \mathrm{s}^{-1}$ & 0.017 \\
\hline
\end{tabular}

Table. 3. DFIG parameter

\begin{tabular}{c|c|c}
\hline $\mathrm{P}_{\mathrm{n}, \text { gen }}$ & $\mathrm{KW}$ & 7.5 \\
\hline $\mathrm{V}$ & $\mathrm{V}$ & $230 / 380$ \\
\hline $\mathrm{f}$ & $\mathrm{Hz}$ & 50 \\
\hline $\mathrm{R}_{\mathrm{s}}$ & $\Omega$ & 0.455 \\
\hline $\mathrm{R}_{\mathrm{r}}$ & $\Omega$ & 0.62 \\
\hline $\mathrm{L}_{\mathrm{s}}$ & $\mathrm{H}$ & 0.048 \\
\hline $\mathrm{L}_{\mathrm{r}}$ & $\mathrm{H}$ & 0.081 \\
\hline $\mathrm{L}_{\mathrm{m}}$ & $\mathrm{H}$ & 0.078 \\
\hline $\mathrm{J}_{\mathrm{r}}$ & $\mathrm{Kg} \cdot \mathrm{m}^{2}$ & 0.3125 \\
\hline $\mathrm{K}_{\mathrm{r}}$ & $\mathrm{N} . \mathrm{m}^{-1}$ & $6.73 .10^{-3}$ \\
\hline
\end{tabular}

Table. 4. Clamping bridge parameter

\begin{tabular}{c|c|c}
\hline $\mathrm{C}_{1}, \mathrm{C}_{2}, \mathrm{C}_{3}, \mathrm{C}_{4}$, & $\mathrm{mF}$ & 1200 \\
\hline $\mathrm{R}_{\mathrm{c}}$ & $\Omega$ & 20 \\
\hline
\end{tabular}

Table. 5. Filter parameter

\begin{tabular}{c|c|c}
\hline $\mathrm{L}_{\mathrm{f}}$ & $\mathrm{H}$ & 0.01 \\
\hline $\mathrm{R}_{\mathrm{f}}$ & $\Omega$ & 0.25 \\
\hline
\end{tabular}


The authors would like to acknowledge the financial support of the Algeria's Ministry of Higher Education and

Scientific Research. This work was supported by L2GEGI laboratory at the University Ibn-Khaldun (Tiaret, Algeria) in collaboration with School of Engineering and Technology, University of Hertfordshire, Hatfield, UK.

\section{REFERENCES}

[1] T. R. Ayodele, A. A. Jimoh, J. L. Munda, and J. T. Agee, 'Challenges of grid integration of wind power on power system grid integrity: A review', world, vol. 3, 2020.

[2] Z. Wang, B. Chen, and J. Wang, 'Decentralized energy management system for networked microgrids in grid-connected and islanded modes', IEEE Trans. Smart Grid, vol. 7, no. 2, pp. 1097-1105, 2016.

[3] Y. Kumar et al., 'Wind energy: Trends and enabling technologies', Renew. Sustain. Energy Rev., vol. 53, pp. 209-224, 2016.

[4] R. Syahputra and I. Soesanti, 'DFIG Control Scheme of Wind Power Using ANFIS Method in Electrical Power Grid System', 2016.

[5] B. Belabbas, T. Allaoui, M. Tadjine, and M. Denai, 'High Order Sliding Mode Controller Simulation by a Wind Turbine for DFIG Protection against Overcurrent', Electroteh. Electron. Autom., vol. 65, no. 4, pp. 142-147, 2017.

[6] X. Liu, S. Laghrouche, M. Harmouche, R. Fellag, and M. Wack, 'Super twisting sliding mode MPPT control of an IM based wind energy conversion system', in Electrical Engineering (ICEE), 2015 4th International Conference on, 2015, pp. 1-5.

[7] B. Belabbas, T. Allaoui, M. Tadjine, and A. Safa, 'Hybrid fuzzy sliding mode control of a dfig integrated into the network', Int. J. Power Electron. Drive Syst., vol. 3, no. 4, p. 351, 2013.

[8] R. K. Patnaik, P. K. Dash, and K. Mahapatra, 'Adaptive terminal sliding mode power control of DFIG based wind energy conversion system for stability enhancement', Int. Trans. Electr. Energy Syst., p. n/a-n/a, Jun. 2015.

[9] M. F. Ansari, S. Chatterji, and A. Iqbal, 'Fuzzy logic-based MPPT controllers for three-phase gridconnected inverters', Int. J. Sustain. Energy, vol. 32, no. 3, pp. 186-195, 2013.

[10] 'Robust fractional order sliding mode control of doubly-fed induction generator (DFIG)-based wind turbines'. [Online]. Available: http://www.sciencedirect.com/science/article/pii/S001905781630026X. [Accessed: 22-Aug-2016].

[11] S.-Y. Yang, Y.-K. Wu, and H.-J. Lin, 'Integrated DFIG-based wind turbine model with direct power control', IEEJ Trans. Electr. Electron. Eng., 2015.

[12] A. Dida and D. Benattous, 'A complete modeling and simulation of DFIG based wind turbine system using fuzzy logic control', Front. Energy, pp. 1-12, 2016.

[13] S. Ghoudelbourk, D. Dib, and A. Omeiri, 'Decoupled control of active and reactive power of a wind turbine based on DFIG and matrix converter', Energy Syst., pp. 1-15, 2015.

[14] C.-M. Hong, T.-C. Ou, and K.-H. Lu, 'Development of intelligent MPPT (maximum power point tracking) control for a grid-connected hybrid power generation system', Energy, vol. 50, pp. 270-279, 2013.

[15] H.-G. Jeong, W. S. Kim, K.-B. Lee, B. C. Jeong, and S.-H. Song, 'A sliding-mode approach to control the active and reactive powers for a DFIG in wind turbines', in Power Electronics Specialists Conference, 2008. PESC 2008. IEEE, 2008, pp. 120-125.

[16] A. Tamaarat and A. Benakcha, 'Performance of PI controller for control of active and reactive power in DFIG operating in a grid-connected variable speed wind energy conversion system', Front. Energy, vol. 8, no. 3, pp. 371-378, 2014.

[17] A. Tarek, H. Abdelaziz, E. Najib, and B. Farid, 'An adaptive backstepping controller of doubly-fed induction generators', in Control, Engineering \& Information Technology (CEIT), 2015 3rd International Conference on, 2015, pp. 1-6.

[18] M. Reddak, A. Berdai, A. Gourma, and A. Belfqih, 'Integral backstepping control based maximum power point tracking strategy for wind turbine systems driven DFIG', in Electrical and Information Technologies (ICEIT), 2016 International Conference on, 2016, pp. 84-88. 
[19] F. Merahi, E. M. Berkouk, and S. Mekhilef, 'New management structure of active and reactive power of a large wind farm based on multilevel converter', Renew. Energy, vol. 68, pp. 814-828, 2014.

[20] D. Arcos-Aviles, J. Pascual, L. Marroyo, P. Sanchis, and F. Guinjoan, 'Fuzzy logic-based energy management system design for residential grid-connected microgrids', IEEE Trans. Smart Grid, vol. 9, no. 2, pp. 530-543, 2018.

[21] F. Mazouz, S. Belkacem, I. Colak, S. Drid, and Y. Harbouche, 'Adaptive direct power control for double fed induction generator used in wind turbine', Int. J. Electr. Power Energy Syst., vol. 114, p. 105395, 2020.

[22] M. M. Aly, E. Abdelkarim, and M. Abdel-Akher, 'Mitigation of photovoltaic power generation fluctuations using plug-in hybrid electric vehicles storage batteries', Int. Trans. Electr. Energy Syst., 2015.

[23] D. Yang, M. Kang, J. Kim, J. Hong, and Y. C. Kang, 'Stable stepwise short-term frequency support of a DFIG-based wind farm', Int. Trans. Electr. Energy Syst., vol. 28, no. 3, p. e2495, 2018.

[24] F. Merahi and E. M. Berkouk, 'Back-to-back five-level converters for wind energy conversion system with DC-bus imbalance minimization', Renew. Energy, vol. 60, pp. 137-149, 2013. 